\title{
ALÉM DE NÚMEROS E ESTATÍSTICAS: O FENÔMENO MIGRATÓRIO SOB UMA PERSPECTIVA ÉTICA
}

\author{
Adilson Pereira* \\ Maria da Conceição Vinciprova Fonseca ${ }^{\dagger}$
}

\begin{abstract}
Resumo
O fim do século XX coroou o avanço da tecnociência como alavancador de uma nova humanidade, cujo primado seria a inovação dos produtos provenientes da revolução tecnológica. Entretanto, o trato humano continuou a ser desafiador para aqueles que se importam com as condições de subumanidade em que se encontram grandes contingentes de pessoas. Neste início do século XXI não se notaram diferenças significativas no trato das populações migrantes, como se observa pelos relatos cotidianos sobre grupos de refugiados em rota de fuga devido às precárias condições de sobrevivência e que não encontram o reconhecimento da sua condição humana nos lugares em que aportaram. Muitos pensadores não veem a globalização econômica como distribuidora das riquezas que a economia global produziu. Os valores inerentes à sociedade globalizada se identificaram com os valores do capitalismo, centrando-se no individualismo e na ideia de que devemos produzir mais, sem levar em conta o esgotamento dos recursos naturais. Tal situação levou muitos autores a produzir uma série de reflexões propondo repensar a ética a partir de uma nova ordem de valores que pudessem considerar as diferenças humanas e estabelecer o minimum ético como princípio garantidor da existência dos humanos. Este trabalho revisita algumas dessas discussões, com um foco específico na questão da migração, almejando um ressignificar de valores que sejam pautados na ética e apontando um horizonte mais favorável à vida, com a aceitação da diferença.
\end{abstract}

Palavras chave: Globalização; Migrantres; Ética.

\section{BEYOND NUMBERS AND STATISTICS: THE MIGRATORY PHENOMENON UNDER AN ETHICAL PERSPECTIVE}

\begin{abstract}
The end of the twentieth century crowned the advance of technoscience as a lever for a new humanity whose primacy would be the innovation of the products of the technological revolution. However, humane treatment has continued to be challenging for those who care about the subhuman conditions in which large numbers of people are found. At the beginning of the twenty-first century, there were no significant differences in the treatment of migrant populations, as can be seen from daily accounts of refugee groups escaping due to poor survival conditions and failing to recognize their human condition in places where Contributed. Many thinkers do not see economic globalization as a distributor of the riches that the global economy has produced. The values inherent in globalized society have identified with the values of capitalism, focusing on individualism and the idea that we must produce more, without taking into account the depletion of natural resources. This situation led many authors to produce a series of reflections proposing to rethink ethics from a new order of values that could consider human differences and establish the ethical minimum as a guarantor of the existence of humans. This paper revisits some of these discussions, with a specific focus on the issue of migration, aiming at a re - meaning of values that are based on ethics and pointing to a more life - friendly horizon, with the acceptance of difference.
\end{abstract}

Keywords: Dodging school; Educational practice; Literacy.

\footnotetext{
* Doutor e mestre em filosofia, área de Ética - UGF/RJ. Docente do Programa Stricto Sensu - Mestrado de Ensino de Ciências da Saúde e Meio Ambiente do Centro Universitário de Volta Redonda - UniFOA e Diretor da FAETECJ/RJ - Faetec-RJ.

${ }^{\dagger}$ Doutora em Letras - Universidade Federal Fluminense, UFF. Docente do Programa Stricto Sensu - Mestrado de Ensino de Ciências da Saúde e Meio Ambiente do Centro Universitário de Volta Redonda - UniFOA.
} 


\section{A globalização econômica e o imperativo de uma nova ética}

O fim do século XX e o início do século XXI não apresentaram diferenças significativas no trato das populações migrantes. Os grupos de refugiados e os que se colocaram em rota de fuga devido às precárias condições de sobrevivência, não encontraram facilidade no trânsito ao destino almejado e, tampouco, o necessário reconhecimento da sua condição humana nos lugares em que aportaram.

Se o fim do século XX coroou o avanço da tecnociência como alavancador de uma nova humanidade, cujo primado seria a inovação dos produtos provenientes da revolução tecnológica, por outro lado o trato humano continuou a ser desafiador para aqueles que se importam, refletem e denunciam as condições de subumanidade em que se encontram grandes contingentes de pessoas. Muitos discursos de líderes e pensadores denunciam o fato de que a globalização econômica não se tornou distribuidora das riquezas que a economia global produziu.

Vale lembrar que o fenômeno da globalização econômica ganhou força no fim do século XX em decorrência do declínio da polarização político-ideológica capitalismo x comunismo e, muito embora a globalização tenha suas raízes na antiga história da humanidade, somente no mundo contemporâneo tornou-se um fenômeno evidente. Considerando a velocidade com que as informações relativas aos mercados financeiros administram somas de trilhões de dólares, e a comunicação que não encontra obstáculo nas diferenças de culturas, idiomas e ideologias, sobretudo pelo uso das redes sociais, além do contínuo fluxo de mercadorias, produtos e serviços, há um novo tipo de deslocamento fluido que não se parece em nada com as rotas comerciais do oriente antigo, nem com o período do mercantilismo ou com os fluxos de mercadorias do capitalismo do neocolonialismo do século XIX.

Em síntese, a globalização impôs a necessária disputa por mercados consumidores e, aliada à tecnociência, sua velocidade tornou-se vertiginosa, de modo que em poucos anos produzem-se defasagens culturais significativas de uma geração para outra. O mundo construído por essa relação estreita entre globalização e tecnociência é apresentado como a construção do admirável mundo novo e, 
resguardando-se as diferenças da obra de Aldous Huxley sociedade globalizada se identificaram com os valores do capitalismo, centrando-se no individualismo, no consumismo, na lógica competitiva, na ideia de que devemos produzir mais e mais, no esgotamento dos recursos naturais, na permeabilidade da vida esgotada nas tarefas que a lógica produtiva impõe.

Enfim, o mundo globalizado tornou-se, com a tecnociência, um espelho virtual que identifica felicidade à conquista de status aliado à aquisição de status e bens materiais.

Contudo, essa não é a realidade em que se encontram milhões de humanos. Para eles, a globalização econômica não foi acompanhada da necessária globalização ética.

Dito sem rodeios, mais pessoas no mundo estão vivendo melhor do que nunca, enquanto muitas vivem cada vez pior. Partes do mundo em desenvolvimento alcançaram padrões de vida repletos de luxo e de supérfluos usufruídos pelas classes médias, que poucos na história humana teriam concebido como possível em tais escalas (MARINOFF, 2007).

Muitos autores, identificando as ameaças que esse modelo representa para a sobrevivência humana, produziram uma série de reflexões propondo repensar a ética a partir de uma nova ordem de valores que pudessem considerar as diferenças humanas e estabelecer o minimum ético como princípio garantidor da existência dos humanos.

Há pensadores, como Leonardo Boff, que insistem na tese de uma ética universal, cujo cerne seria a humanitas, isto é, residiria nesse princípio ético a obrigatoriedade de tratarmos humanamente a todos, independente da situação de classe, religião, idade. (BOFF, 2000).

Considerada dessa forma, a ética, concebida como o minimum ético, toma o humano como valor fundamental e não o dissocia da natureza, pois da integração de ambos, homem-natureza, depende a sobrevivência humana. Esse minimum ético requer diálogo entre as culturas, religiões, ideologias políticas, legisladores, enfim, diálogo de todos os atores envolvidos na tarefa de obrar por um mundo em que as gerações possam vislumbrar um horizonte menos nebuloso do que o que se avizinha na atualidade.

\footnotetext{
‡ Na obra Admirável Mundo Novo, de Aldous Huxley, publicada em 1932, era concebida uma sociedade perfeita, cujos membros seriam condicionados psicologicamente à obediência às regras. $O$ autor escreveu, mais tarde, outra obra, o Retorno ao Admirável Mundo Novo, um ensaio em que demonstrava que muitos aspectos de sua ficção estavam sendo realizados graças aos avanços técnicocientíficos.
}

RPI Revista de Pesquisa Interdisciplinar, Cajazeiras, v. 1, n. 1, 79-90, jan/jul. de 2017. 


\section{Ética e migração: necessária aproximação}

Ao enunciarmos a possibilidade de uma ética do humanitas, cujo minimum ético resguarde os valores fundamentais de proteção à humanidade, estamos sinalizando que essa ética deve considerar a todos os humanos como inclusos em seu círculo hermenêutico. Sua necessidade se torna evidente quando as condições de negação da humanidade se tornam igualmente evidentes. Se por um lado evidenciamos que grandes contingentes humanos se submetem ao fluxo migratório por causa das guerras, desastres naturais, desgaste econômico nacional ou regional, um elenco enorme de outras causas precisa ser considerado para definir o propósito que implica em migrar.

Por outro lado, nossa reflexão se desdobra nas consequências desse fenômeno; afinal, o migrante é, antes de tudo, portador de diferenças significativas e, por isso, passível de ser identificado como ameaçador à cultura, à identidade e ao sentido que uma sociedade constrói para si mesma. Concebida, mas não reduzida a um fenômeno de natureza político-social, a migração é rica em fenômenos sociais decorrentes de seu aparecimento que impactam os pesquisadores das ciências sociais e humanas.

Estamos nos referindo à violência xenófoba, a minimização intencional da garantia dos direitos primários, ao reducionismo da mão-de-obra migrante à esfera da economia informal, aos preconceitos inseridos culturalmente pelos meios de comunicação social, aos impeditivos de inserção nos espaços formais de educação, entre outros tantos aspectos decorrentes do simples fato de o sujeito estar sob o rótulo de migrante e, portanto, portador de evidentes diferenças culturais.

Uma pergunta possível na condução de nossa reflexão seria: porque, sendo humanos, somos assim? Teríamos a tendência de rejeitar os humanos diferentes? Por outro lado, haveria uma natureza humana que poderia ser considerada como universal, aquém das diferenças dos sujeitos? Que significado teria essa concepção de natureza humana no estabelecimento de um minimum ético?

A tentativa de reflexão acerca dessas questões poderia ser sintetizada nas reflexões de determinados intelectuais, provenientes das mais diversas áreas das ciências, que tentam compreender esses problemas. Nosso propósito aqui não é o de analisar com profundidade essas questões, mas elas são necessárias como auxílio à nossa reflexão. Na realidade, os argumentos propostos para a reflexão dessas questões dão conta de um mosaico de teorias que transitam desde as contribuições das ciências biológicas até às ciências humanas e sociais. Responder às questões relativas à natureza 
humana ainda é um desafio aos círculos intelectual e acadêmico, que tentam compreender o humano de modo que esse conceito se torne ressignificado, uma vez que essa ressignificação é de suma importância para a construção e condução de políticas públicas, legislações, entre outras contribuições.

Se, por um lado, temos pesquisadores que tentam compreender os problemas relativos à natureza humana de modo geral, por outro lado há aqueles que se colocam como investigadores dos fenômenos relativos à migração, de forma específica, e que se identificam com esse objeto de estudo. Conduzidos por curiosidade instigante, tentam compreender os múltiplos aspectos implícitos no fenômeno da migração e têm como meta poder auxiliar a minimizar os problemas dos que migram com o resultado de suas pesquisas.

Retornando às questões propostas anteriormente, recorremos à Ética. Afinal, uma das tentativas de melhor compreensão das questões relativas ao trato humano estaria na necessária reflexão teórica sobre o nosso agir moral e, nesse sentido, a ética, como disciplina filosófica, pode ser oportuna para desnudar o problema da rejeição que muitos nutrem sobre aqueles que são portadores de diferenças.

Se, contudo, necessitamos de um conjunto de regras prescritivas sobre o modo como devemos nos comportar, e a isso denominamos moral, ainda assim devemos saber que a moral é uma esfera dinâmica, construída na confluência dos valores que herdamos culturalmente, seja por herança religiosa, ideológica, enfim, dos valores que tornamos senso comum em nosso cotidiano e que se aglutinam à nossa realidade, fornecendo-nos um sentido identitário de pertença social e cultural.

O fenômeno da mobilidade humana implicaria num confronto de diferenças relativas ao universo moral advindo da tradição de uma sociedade em que se entende que sujeitos provenientes de uma cultura, poderiam confrontar outra cultura, emergindo dessa relação os conflitos sociais.

Uma posição contrária a esse argumento seria o fato de a experiência demonstrar que humanos de diferentes culturas podem habitar e conviver num mesmo espaço social sem que isso desborde, por exemplo, em violência xenófoba. Contudo, quando, no mundo contemporâneo, a migração se tornou facilitada pelos meios de locomoção, teria surgido um fenômeno novo: o estranhamento do migrante.

O sujeito migrante, visível para a sociedade que o recebe, não representa singularmente uma ameaça ao princípio identitário, mas tornado associado a inúmeros 
outros migrantes torna-se a representação de que a negação identitária estaria a caminho da cultura em que ele aportou.

Não são poucos os exemplos que temos de como esse fenômeno é rico em crueldade por parte dos que se consideram ameaçados, partindo para formas de violência que vão desde a implementação de legislações absurdamente restritivas até a violência moral, mental e física.

Por outro lado, no âmbito da ética, a resposta a esse fenômeno estaria em teorias que postulam a universalidade do homem. O humano estaria designado e reconhecido, por reconhecimento da razão, como um ente universal, dotado de direitos fundamentais e inalienáveis, tais como o direito natural à vida, dignidade e outros que devem ser protegidos por aqueles que se colocam ao lado da racionalidade.

Dentre as teorias éticas que se destacam nessa perspectiva estão a ética cristã, cujo princípio da razão seria partícipe da criação e, portanto, natural à existência dos seres humanos, eles próprios criaturas dotadas de essência universal e endereçados à felicidade.

Há ainda a ética deontológica, que torna o dever o princípio ético que validaria as ações morais como ações protetivas à humanidade e em cujo círculo de proteção encontram-se, sobretudo, os humanos em condição de maior vulnerabilidade. Destacamos aqui, de modo particular, as comunidades migrantes.

Outro escopo ético é a ética do cuidado, emergente da crítica à dominação humana sobre a natureza e o mundo da vida. Nessa perspectiva ética, as teorias convergem na aceitação de que a universalidade humana seria o primado que implicaria em afirmar que a natureza se harmonizaria no conjunto de todas as diferenças que concorrem para seu pleno equilíbrio.

Não nos referimos à natureza somente como ecologia - oikos (casa), logos (razão) -, tomada em separado como objeto de análise das ciências biológicas; ao contrário, nela consideramos a natureza humana como inclusa, concebida como totalidade de relações dos seres e, partindo-se do pressuposto de que os seres na natureza se relacionam tendo por princípio a harmonia das diferenças, compreendemos ser esse o princípio que deveria nortear a comunidade humana. A diferença, problema emblemático no trato das populações migrantes, pode ser elemento de complementaridade das relações. 


\section{Por uma ética do cuidado e da humanidade}

O século XXI, ainda em seu início, pode ser considerado a extensão do quadro de crise do final do século XX. A crise da economia americana e, atualmente, a crise da economia europeia e o efeito dominó estendido a inúmeros países de economia frágil (dentre eles países da América Latina, da África e Ásia), ainda não findou.

A natureza, por sua vez, tem respondido às agressões sofridas pelo trato que lhe foi delegado nos últimos séculos de exploração de recursos endereçados ao funcionamento do maquinário econômico produtivo, de sorte que as mudanças climáticas são, portanto, uma realidade inegável.

Associados a esses elementos, devemos inserir aqueles relativos aos problemas ideológicos, que tornam o poder o elemento central das disputas políticas, incitadas por concepções religiosas dogmáticas e partidárias, como também a disputa pelos recursos provenientes da natureza, seja a terra, a água etc. Esse amálgama de fatos não responde de forma pacífica ao intento de se tratar humanos a partir do reconhecimento de sua humanidade. Ao contrário, a tendência do acirramento ideológico é relegar populações inteiras à sua própria sorte. Essas, por outro lado, tomam por norte o princípio da sobrevivência, que lhes é caro, já que mover-se em função de dias melhores lhes é a única alternativa possível.

Para essa população migrante, o vislumbre de uma sociedade cosmopolita se concretiza, em seu imaginário, naqueles Estados tidos como porto de maior segurança para a sobrevivência. Nesse sentido, a figura migrante está, com certeza, muito mais presente nos grandes centros do mundo que mantêm uma situação de conforto e segurança, a despeito de problemas enfrentados.

Vem então a pergunta: como estão sendo incluídos os migrantes no quadro dessas sociedades? A resposta está na evidência da presença desses grupos na inserção econômica de baixa remuneração, aquela que move a economia industrial ou em serviços a que os migrantes se submetem sem a integralidade e garantia dos direitos fundamentais.

A inserção na economia informal ou na economia formal de baixa remuneração certamente não resolvem o problema da inclusão das diferenças, ao contrário, a evidencia como substrato próprio do universo migrante.

Como indicamos anteriormente em nossa reflexão, essa possibilidade de construir uma inserção de qualidade estaria na construção de uma ética humana RPI Revista de Pesquisa Interdisciplinar, Cajazeiras, v. 1, n. 1, 79-90, jan/jul. de 2017. 
universal. O problema que nos parece imediato é: há possibilidades de tal projeto tornar- se exequível?

Os escritos de Hans Küng (1993) oferecem contribuição significativa a essa questão. Sua pesquisa propõe uma análise da maior parte dos problemas que as sociedades contemporâneas enfrentam e, para afastar o risco de tomarmos um projeto de tal ordem como sendo utópico, é preciso termos a clareza de que ele oferece uma excelente alternativa de garantia para nossa sobrevivência no mundo.

O alarme diante da situação da distribuição - e redistribuição - das pessoas no mundo é justificado não apenas pelo senso comum, mas também com os mais diversos trabalhos científicos que apontam a deterioração da natureza e das sociedades, levando a refletir sobre quais posturas protetoras deveriam, ou melhor, precisariam, ser multiplicadas imediatamente.

Küng denomina seu projeto de Ética Mundial e o propõe como uma moral ecumênica. A referência clara às religiões não está desvinculada da evidência de que elas ainda guardam a força indicativa sobre como nortear a ação humana, e que o mínimo consenso - o minimum ético - poderia ser expresso pelas religiões sob a forma de diálogo ecumênico.

Essa lógica também seria aplicada aos Estados. "Todos os Estados do mundo têm, com certeza, uma ordem econômica e jurídica. Mas em nenhum Estado do mundo ela funcionará sem um consenso ético, sem uma ética dos cidadãos, do qual vive o Estado de direito democrático.” (KÜNG, 1993.).

Ainda sobre essa questão, Küng nos diz:

Hoje em dia, a comunidade mundial não pode mais dar-se ao luxo de uma ética divergente e até contraditória em pontos centrais. O que adianta ter proibições eticamente fundamentadas em um determinado país se num outro país elas podem ser burladas? Pensemos somente em determinadas manipulações financeiras ou da bolsa de valores ou em arrojados projetos de pesquisa genética. Se a ética deve funcionar para o bem de todos, ela deve ser indivisível. O mundo não dividido necessita mais e mais de uma ética não dividida. (KÜNG, 1993, p.58).

Guardadas as diferenças teóricas, essa perspectiva também é enunciada pelo filósofo alemão Jügen Habermas, que concebeu a teoria da ação comunicativa e a tornou elemento constituinte na interpretação do papel das democracias contemporâneas, tendo como pressuposto o consenso. Segundo Habermas, 
...não é a relação de um sujeito solitário com algo no mundo objetivo que pode ser representado e manipulado, mas a relação intersubjetiva, que sujeitos que falam e atuam assumem quando buscam o entendimento entre si, sobre algo. Ao fazer isto, os atores comunicativos movem-se por meio de uma linguagem natural, valendo-se de interpretações culturalmente transmitidas e referem-se a algo simultaneamente em um mundo objetivo, em seu mundo social comum e em seu próprio mundo subjetivo (1984, p. 392).

Os sujeitos a que Habermas se refere são os partícipes de uma sociedade marcada pelas diferenças desses sujeitos. A intersubjetividade só ocorre, de fato, entre diferentes.

Eis o ponto central de nossa defesa quanto à acolhida do migrante. A acolhida às diferenças não eliminaria a identidade cultural do acolhedor; ao contrário, a enriqueceria.

Existe muito da memória cultural para aprender e ressignificar. Essa convivialidade indicaria o exercício da tolerância como pressuposto ético, o ecumenismo como significação religiosa e a garantia dos direitos como elemento fundamental dos Estados que são marcados por esse humanismo. Essa perspectiva do consenso como elemento ético fundamental nos parece irrevogável. Segundo Küng:

Hoje, ninguém mais precisa ser contra as "conquistas modernas", contra a liberdade, a igualdade e a fraternidade só porque crê em Deus. Hoje, as orientações religiosas sobre a realidade não excluem mais a cosmovisão científica. Também a fé religiosa não exclui mais o engajamento político. (...) Através da relação especial da pessoa humana com Deus ("imagem de Deus") pode ser fundamentado de forma radical aquilo que ultrapassa o empírico:

-a inviolabilidade da pessoa humana;

- a liberdade inalienável da pessoa;

- a igualdade fundamental de todas as pessoas;

-a necessária solidariedade entre todas as pessoas. (KÜNG, 1993, p. 98).

O reconhecimento desses valores fundamentais como tarefa da razão é, certamente, inegável. O reconhecimento desses valores no plano formal das legislações também é inegável.

Guardadas as diferenças de Estados, esses princípios são reconhecidos como válidos, sobretudo, pelos países de tradição democrática. O problema residiria no escopo ético - que só se torna possível quando exercitado. Sem dúvida, a ética proposta 
por Aristóteles (séc. IV a.C.) já indicava o exercício do bom hábito como constituidor das virtudes.

Segundo Comte-Sponville, o bem residiria na pluralidade das boas ações e das boas disposições, também elas plurais, e a esse bem chamaríamos virtude ou excelência moral. (COMTE-SPONVILLE, 1995). Assim, não há humano pronto, acabado, plenamente virtuoso. O humanizar-se é um processo contínuo e uma ética do humano se inscreve na realidade como uma ética do cuidado.

Assim, não há cuidado sem o exercício do cuidar, sem a prática cuidadosa.

Basta o simples exemplo do quanto nossas coisas cotidianas se deterioram quando não lhes damos a devida atenção, pois não há planta que sobreviva, não há criança que se eduque, não há relacionamento amoroso que perdure, não há.

Essa última afirmação (não há) indica o quanto a negação pode ser ameaçadora à nossa sobrevivência. Num mundo em que construímos a figura dos negados, a figura dos migrantes, em particular destaque nesse trabalho, não pode ser relegada à condição de negação; afinal, as negações desenvolvem uma realidade que lhes é própria, a marginalidade, e todos nós sabemos o quanto a marginalidade social envenena o convívio.

Se queremos preparar terreno com vistas a dias melhores para as gerações que estão a caminho, não podemos lhes negar um mundo de incluídos, sejam membros de culturas diferentes, religiões diferentes, etnias diferentes, enfim, humanos diferentes, mas iguais em direitos e responsabilidades.

Por último, a memória do primeiro artigo da publicação intitulada "Construção do mapa da imigração no Estado do Rio de Janeiro: Explorando os dados do Censo Demográfico" nos é significativa. As reflexões delineadas sobre uma ética humana e do cuidado permitem olhar o mapeamento para além dos números, tabelas e gráficos apresentados no discurso contemporâneo hegemônico como marcas de um contexto de aparente equilíbrio das relações sociais.

Se a pesquisa traz dados que, de imediato, podem ser lidos como demonstrativo estatístico acerca da presença da população migrante constante do Estado do Rio de Janeiro, mas que registram um mosaico de como a ordem dos valores baseada na diferença humana, proveniente de diversas culturas desse equilíbrio, é tida aos olhos do senso comum como algo evidenciado, para os olhos da investigação ética não seria bem assim. 
Por trás dos números, temos as existências de muitos; temos as pessoas. E nelas, temos também as marcas dos desejos e buscas que se iniciaram em algum momento da vida e que encontram, na realidade, as limitações estabelecidas pela Lei, pela moral, pela cultura, pelo idioma, pela economia, pela política; enfim, pela realidade desafiante até para os que nasceram no solo brasileiro. Incluí-los é um imperativo ético. Nas palavras de Küng, no limiar do século XXI:

Para o próximo milênio devemos achar um caminho para a diversidade de culturas, tradições e povos na Europa, que
forma reconciliada. Para isso são necessários alguns passos:

- devem ser superadas as divisões excludentes, que são promovidas por discriminações raciais, étnicas e culturais;

- $\quad$ deixar de lado a marginalização de dois terços do mundo;

- deixar pra trás a herança do anti-semitismo e suas trágicas consequências em nossas sociedades e em nossas igrejas.

Necessário se faz uma ordem mundial pluralista! (KÜNG,1993, p. 99).

Esse nos parece o aspecto desafiador implícito na leitura dos números e gráficos. Para muitos, uma descoberta do quanto existem, no Rio de Janeiro, segmentos de migrantes de diversas culturas e valores distintos. Conhecer como estão incluídos é outro trabalho e mais um desafio.

\section{Considerações finais}

Se a Ética do humano e do cuidado - como proposta de uma ética universalista - já ecoa nos mais diversos círculos intelectuais e religiosos; e se sua influência já se encontra representada em uma gama de legislações protetivas e programas governamentais através de políticas públicas que pensam a inclusão dos sujeitos socialmente vulneráveis, vemos nisso um sinal de significativo avanço para a acolhida e inclusão das populações migrantes.

Mas, conforme refletimos, o exercício ético é necessário e, em última instância, ele também depende de intervenções no espaço formal de educação.

$\mathrm{Na}$ situação de educadores, vale sempre insistir que a escola é partícipe da transformação que uma sociedade almeja. Trata-se de uma revolução silenciosa, segundo alguns autores, mas necessária e contínua ao longo de algumas gerações. 
Assim, podemos pensar no horizonte de dias melhores, porque podemos nos tornar melhores e mais humanos com os outros humanos. Utopia, diriam alguns.

Contudo, passos estão sendo dados, ideias estão sendo comunicadas, condutas estão sendo alteradas, leis estão sendo instituídas e a utopia vai se dissipando, deixando em seu lugar o indeterminado aparecer.

Sim, ainda soa como indeterminado, mas o mundo mais ético em que a vida com qualidade seja o maior valor pode estar muito mais próximo de ser encontrado.

Talvez a presença de reflexões como as trazidas aqui possa ajudar a dar propulsão ao desejado vento da mudança.

\section{Referências}

BOFF, Leonardo. Ethos mundial: um consenso mínimo entre os humanos. Brasília: letraviva, 2000.

COMTE-SPONVILLE, André. Pequeno tratado das grandes virtudes. Tradução de Eduardo Brandão. São Paulo: Martins Fontes, 1995.

HABERMAS, J. The theory of communicative action. Vol 1. Reason and the rationalizalion of society. Boston: Beacon Press. 1984.

KÜNG, Hans. Projeto de ética mundial: uma moral ecumênica em vista da sobrevivência humana. Tradução de Haroldo Reimer. São Paulo: Paulinas, 1993.

MARINOFF, Lou. O caminho do meio. Como encontrar felicidade em um mundo de extremos. Tradução de Paulo Lemos e Márcia Sobreiro. Rio de Janeiro: Record, 2008.

TUGENDHAT, Ernest. Lições sobre ética. Tradução grupo de doutorandos do curso de pós-graduação em filosofia da universidade do Rio Grande do Sul; revisão e organização Ernildo Stein e Ronai Rocha. Petrópolis: Vozes, 1996. 